UDC 316.342

LBC 60.524-60.56

\title{
RURAL RESIDENTS OF THE SOUTH OF RUSSIA ABOUT THE PRESENT AND FUTURE OF THE VILLAGE (ANALYSIS OF THE 2018 QUESTIONNAIRE SURVEY) ${ }^{1}$
}

\author{
Ludmila V. Namrueva \\ Kalmyk Scientific Center of the Russian Academy of Sciences, Elista, Russian Federation
}

\begin{abstract}
The modern Russian village has been going through difficult times for more than three decades. This was manifested in the elimination of a huge number of agricultural enterprises, the growth of socio-economic problems, and the irrevocable migration of the rural population. The social and property differentiation of farms and the villagers themselves indicates different economic models of behavior, different adaptive capabilities of the population, and the presence / absence of rural resources. Some rural areas are leaders, profitable; others, on the contrary - are outsiders, weak. The author analyzed the regions of the Republic of Kalmykia, Astrakhan oblast, Volgograd oblast, Stavropol Krai - has traditionally been a barn, providers, suppliers of primary agricultural products - meat, grain, milk, oil, grease, wool, vegetables, and fruits. At present, when all financial flows are concentrated in the capital and several major cities, these southern Russian regions, while continuing to supply all the same products, are in an unequal position with the leaders of the country's economic development. On their territories, of course, there are profitable agricultural enterprises, but most rural settlements do not belong to such, on the contrary, they are depressed and gradually disappear. The article deals with the problems of the rural population of the agrarian regions of the South of Russia. The prolonged crisis and the simultaneous decline in agricultural production led to the degradation of rural areas and a decline in the standard of living of the rural population. The main problems remain the lack of employment, low incomes, and the active outflow of the rural population.
\end{abstract}

Key words: rural territories, rural population, agricultural sector, unemployment, migration, southern Russian territories.

Citation. Namrueva L.V. Rural Residents of the South of Russia About the Present and Future of the Village (Analysis of the 2018 Questionnaire Survey). Logos et Praxis, 2021, vol. 20, no. 3, pp. 123-129. (in Russian). DOI: https://doi.org/10.15688/lp.jvolsu.2021.3.12

УДК 316.342

ББК $60.524-60.56$

\section{СЕЛЬСКИЕ ЖИТЕЛИ ЮГА РОССИИ О НАСТОЯЩЕМ И БУДУЩЕМ СЕЛА (АНАЛИЗ АНКЕТНОГО ОПРОСА 2018 г.) ${ }^{1}$}

\author{
Людмила Васильевна Намруева \\ Калмыцкий научный центр РАН, г. Элиста, Российская Федерация
}

\begin{abstract}
Аннотация. Современное российское село переживает затянувшийся на 3 десятилетия кризис, который проявился в ликвидации огромного числа сельхозпредприятий, безвозвратной миграции сельского населения, обезлюдении огромных территорий. К счастью, некоторые села не исчезли, продолжают функционировать, часть даже весьма успешно. Социальная, имущественная дифференциация хозяйств, самих сельчан свидетельствует о разных экономических моделях поведения, об отличающихся адаптаци๘ онных возможностях населения, наличии / отсутствии ресурсов деревень. Одни сельские территории 芩 лидеры, являются рентабельными; другие, наоборот, - аутсайдеры, оказываются слабыми. Если сельские жители первых материально благополучны, то во второй категории бедствуют. Анализируемые автором регионы - Республика Калмыкия, Астраханская область, Волгоградская область, Ставропольский край - традиционно являлись житницами, кормильцами в государстве, поставщиками основных сельс-
\end{abstract}


кохозяйственных продуктов - мяса, зерна, молока, шерсти, овощей, фруктов. В настоящее время, когда все финансовые потоки сосредоточены в столице и нескольких крупных городах, указанные южнороссийские регионы, продолжая поставлять всю ту же продукцию, находятся в неравном положении с лидерами экономического развития страны. На их территориях, конечно, находятся рентабельные сельхозпредприятия, однако большинство сельских поселений не относятся к таковым, напротив, они депрессивны и постепенно исчезают. В статье рассмотрены проблемы сельского населения аграрных регионов Юга России. Продолжительный кризис и одновременно с ним происходящий упадок сельхозпроизводства привели к деградации сельских территорий, снижению уровня жизни сельского населения. Главными проблемами остаются отсутствие занятости, низкие доходы, активный отток сельского населения. Вместе с тем анкетирование показало, что респонденты в сложных сельских реалиях ориентируются в первую очередь на себя. По мнению 40 \% опрошенных, в селе заметно улучшение жизни, а также отдельных сторон социальной инфраструктуры.

Ключевые слова: сельские территории, сельские жители, аграрная отрасль, безработица, миграция, южнороссийские регионы.

Цитирование. Намруева Л. В. Сельские жители Юга России о настоящем и будущем села (анализ анкетного опроса 2018 г.) // Logos et Praxis. - 2021. - T. 20, № 3. - C. 123-129. - DOI: https://doi.org/10.15688/ lp.jvolsu.2021.3.12

\section{Введение}

С начала нового столетия отечественные социологи активно исследуют сельские территории, социально-экономические ресурсы сел, демографический потенциал реализации программ по продовольственной безопасности России, внешние и внутренние миграционные процессы [Бадмаева 2017; Бадмаева 2018; Великий 2019; Калугина 2016; Namrueva 2019; Nuskhaeva 2019]. В нашей статье проанализированы данные анкетного опроса, проведенного в вышеуказанных южнороссийских регионах.

Невозможно анализировать состояние сельских территорий без понимания их как части социальной системы. Совершенно верно В. Жалсанова замечает, что «село не может существовать автономно и соответственно является полноправным субъектом всех социальных преобразований, и процессов социальной трансформации в том числе» [Жалсанова 2016, 11]. Селу не хватает имеющихся социальных, экономических, инфраструктурных ресурсов, это не позволяет ему равноценно отвечать постоянно возникающим вызовам (санкции западных государств, диспаритет цен на сельхозпродукции и т. д.). Задачи нашего исследования направлены на то, чтобы рассмотреть оценку, данную сельскими жителями на ситуацию в селе, разнообразных факторов, влияющих на настоящее и будущее сельских территорий южного макрорегиона.
На основе массового анкетного опроса уточнены факторы, оказывающие влияние на жизнедеятельность сельского населения Республики Калмыкия, Астраханской и Волгоградской областей, Ставропольского края. В статье проанализированы данные пилотажного социологического исследования, проведенного осенью 2018 г. в вышеуказанных регионах. Опрошено 400 человек, по сотне - в каждом, мужчины и женщины представлены в равной мере. Отметим, что на Юге России отсутствует опыт проведения аналогичных исследований по данной проблематике [Намруева 2020, 78]. В Калмыкии опрос провел сам автор статьи, в остальных регионах он осуществлен студентами, которые обучаются на социологов в вузах Астрахани, Волгограда, Ставрополя. В силу того, что выборочная совокупность недостаточна для анализа в региональном распределении, полученный материал автором проанализирован в гендерном разрезе. Результаты анкетирования позволили выделить наиболее значимые проблемы села в условиях нестабильности: финансовые условия развития хозяйств, государственная политика в аграрной отрасли.

Рабочей гипотезой нашего исследования является предположение об усилении кризиса в сельских районах, скептического отношения населения к изменениям в сельской местности, об упадке сельхозпроизводства, о снижении уровня жизни сельского населения и росте патернализма у селян. 


\section{Оценка сельским населением ситуации в южнороссийских селах}

Непродуманные бесконечные преобразования аграрной сферы обрекли десятки тысяч сел на исчезновение с карты страны. Еще в 2009 г. известный социолог села А.А. Хагуров, цитируя демографов, констатировал, что «в России каждый день вымирает по 2 деревни» [Хагуров 2009, 95]. Несмотря на эти катастрофические явления, оставшиеся сельские жители стали постепенно адаптироваться к аграрным реформам, у них значительно трансформировались потребности, жизненные установки, поведение. В связи с этим растет число тех, кто, принимая изменчивую сельскую действительность, стремится здесь реализовать свой потенциал, продвинуться по социальной лестнице.

Один из закрытых вопросов анкеты определял, на кого более всего полагаются сельские жители в решении злободневных вопросов. Результаты показали, что 82,4 \% рассчитывают в первую очередь только на себя. Можно заключить, что постепенно исчезают патерналистские ожидания сельских жителей, они стали больше полагаться на собственные силы и возможности. Причем среди них женщин $(85 \%)$ несколько больше, чем мужчин (80 \%). И те, и другие во вторую очередь полагаются на своих родственников и друзей $(38,6 \%)$. В этом случае наблюдается обратная картина: мужчин, надеющихся на родственные и дружеские связи (40 \%), незначительно больше, нежели женщин (37,3 \%). Третьим институтом народной надежды выступает российское правительство, этот ответ сильно уступает предыдущим (10,8 \%). Остальные институты, предложенные нами «местные (районные и сельские) власти» $(5,6 \%)$, «региональная власть» $(3,5 \%)$, «этническая и религиозная община» $(2,2 \%)-$ набирают малое количество респондентов. При этом женщины в меньшей степени, чем мужчины, рассматривают указанные институты в качестве значимых в своей жизни. Исходя из полученных данных, можно резюмировать, что происходит такое явление, как отчуждение власти, которая занята своими управленческими функциями, особо не вникая, каким образом выживают простые селяне в суровых рыночных условиях. Можно заключить, что аутсайдеры нашего списка реально не участвуют в оказании помощи сельскому населению.

Мнение опрошенных сельчан относительно положительных изменений в селе за последние 3 года оказалось противоречивым. Так, половина опрошенных (49,8 \%) и мужчин, и женщин считают, что жизнь в селе никак ни улучшилась. Другая половина, напротив, видит положительные изменения. Женщины склонны замечать в большей степени, чем мужчины, улучшения в социальной сфере (наличие водопровода, газоснабжения, ремонт асфальтированной дороги) (мнение 26,2 \%) и также повышение доходов односельчан $(10,7 \%)$. Мужчины отмечают такие позитивные результаты, как развитие личных подсобных хозяйств (14,8 \%), получение молодыми специалистами жилья (10 \%).

Респондентами независимо от гендерной принадлежности отмечены в равной степени такие важные изменения, как рост цен на сельскохозяйственную продукцию - зерно, мясо, шерсть - (14,1\%), улучшения в социальной инфраструктуре (15,3 \%). В некоторых селах открыты детские дошкольные учреждения, построены стадионы, где местное население охотно занимается.

Бесспорно, кардинальные преобразования в стране, связанные с увеличением финансовой поддержки агропромышленной отрасли (значительные инвестиции, субсидии, направленные на развитие сельских территорий, семейно-потребительского уклада (ЛПХ), семейно-предпринимательского уклада $(К Ф Х))$, оказали положительное влияние на многие стороны жизнедеятельности селян, их социальное самочувствие. Согласно разделяемому нами мнению М.Н. Мухановой, «ЛПХ, фермерские хозяйства... на селе выполняют важную социальную функцию. Они канализируют издержки социального развития российского общества в виде поглощения трудовых ресурсов, которые остались бы не у дел. Это одно из объяснений причин относительной социальной стабильности на российском селе» [Муханова 2018, 132]. Вместе с тем следует отметить, что нерешенными остаются проблемы, связанные с повышением доходов, трудовой занятостью сельчан, предоставле- 
нием жилья молодым специалистам, приобретением новой сельхозтехники.

Итоги анкетного опроса позволяют определить мнение селян о том, в чем в первую очередь нуждается село, основная его сфера - сельское хозяйство. Исходя из полученных результатов, сформируем список приоритетных задач сельских населенных пунктов исследуемых южнороссийских регионов. К ним отнесены: достойная оплата труда сельских тружеников (мнение 36,3 \%), хороший руководитель, который способен вывести хозяйство на новый уровень развития (24,2 \%), закрепление молодежи на селе (17,7 \%). Ответы мужчин и женщин особо не различаются. По мнению 14,7 \% респондентов, село и аграрная сфера нуждаются в обновлении техники, в передовых технологиях (12,3 \%). Имеющиеся в настоящее время слабые инвестиционные ресурсы не способны обеспечить прорыв отечественного АПК, который сильно зависим от техники и технологий, приобретаемых из дальнего зарубежья.

Полученные итоги анкетирования показывают, что более трети нашего массива важным считают обеспечение достойной оплаты труда сельчан. По утверждению А.И. Алтухова, академика РАН, «уровень оплаты труда работников сельскохозяйственной отрасли составляет лишь 57 \% к среднему показателю по экономике. Почти у 40 \% работающих в сельскохозяйственных организациях зарплата ниже прожиточного минимума трудоспособного населения» [Алтухов 2018 , 6]. Н.Н. Минеева в своей статье развивает эту тему: «Номинальная заработная плата населения сельских территорий, занятого в сельском хозяйстве, почти в 2 раза ниже среднего показателя по экономике страны в целом. При этом оплата труда практически не связана с качественными характеристиками рабочей силы, образованием и квалификацией работника, условиям и труда, организационно-техническим оснащением, а обусловлена, в основном, уровнем экономического развития региона или отрасли» [Минеева 2020, 146].

Низкая заработная плата, отсутствие занятости сельчан приводят к росту бедных. Так, исследователи отмечают, что «доля малоимущих среди сельского населения всего по стране составляет 23,5 \%, а доля малоимущих среди городского населения - 9,1%. Таким образом, доля малоимущих в сельской местности представляет почти четверть сельского населения, что почти в два раза больше, чем таковая в целом по всему населению страны и почти в три раза больше, чем соответствующая доля среди горожан» [Сальников 2020, 15]. Используя расчеты С.Г. Сальникова, остановимся на анализе доли малоимущих в исследуемых нами регионах. Так, «в Астраханской области доля малоимущих составляет 28,5 \% от сельского населения, в Волгоградской области - 31,9\%, в Ставрополье - 29,6 \%, в Калмыкии - 30,8 \%» [Сальников 2020, 15]. Как видим, доля малоимущих в анализируемых нами регионах превышает таковую долю среди сельчан по всей стране $(23 \%)$.

Полученные результаты свидетельствуют, что одной из приоритетных задач изменения жизни села является наличие руководителя, знающего, как обустроить жизнь на селе. К сожалению, в сельскохозяйственной отрасли катастрофически не хватает руководителей, которые способны вывести коллективное предприятие из тупика, предложив новые направления развития. Наше исследование показывает важность такого фактора, как эффективный менеджмент на селе. В связи с этим полностью разделяем выводы авторитетных социологов села - П.П. Великого, Е.В. Бочаровой - о том, что «менеджмент крупхозов и фермеры ограничиваются заботой о небольшой доле сельских сообществ, которой посчастливилось получить работу, и они входят в производственный персонал. Современный крупхоз очень мал и по масштабам производства, и по числу занятых - не более вчерашней колхозной бригады или отделения совхоза. Люди, оставшиеся вне вновь созданной системы (8 из 10 млн, ранее имевших рабочие места), должны были позаботиться о себе сами, находить каналы источников выживания» [Великий, Бочарова 2014, 31]. В начале данной статьи акцентировали внимание на том, что жители современных сел стали больше полагаться на свои силы и возможности, нежели на помощь со стороны, в решении важных проблем, избавляясь от патерналистских ожиданий. 
Острой социальной проблемой для многих российских субъектов, в том числе и анализируемых регионов, является безвозвратная миграция за пределы сельских территорий, исчезновение сел. Н.В. Бадмаева отмечает, что «стремление жить в городах имеет глубокое социально-экономическое обоснование: уровень занятости населения, развитие различных форм социальной защиты, жилищных условий в городе выше, чем в сельской местности» [Бадмаева 2017, 113]. Однонаправленные урбанизационные процессы, к сожалению, нарастают, наиболее сильным миграционным настроениям подвержены молодые люди. В связи с этим проблема закрепления молодежи на селе по итогам нашего анкетирования названа одной из самых насущных.

Банкротство, ликвидация сельхозпредприятий, потеря работы, отсутствие источников выживания способствуют тому, что селяне, окончательно разуверившись в благополучие села, активно мигрируют, стремясь решить множество своих злободневных проблем. По мнению Н.В. Бадмаевой, наиболее притягательными регионами для мигрантов из рассматриваемых регионов являются Центральный (г. Москва), Северо-Западный (г. СанктПетербург), Уральский федеральные округа [Бадмаева 2018, 158].

Результаты на закрытый вопрос анкеты показали, каково миграционное поведение сельских респондентов рассматриваемых регионов.

Жизнь в сельских населенных пунктах, в большей степени не удовлетворяющая его жителей, усиливает их мотивацию на отъезд (см. таблицу). В этом стремлении обнаружены различия в гендерном разрезе. Так, опрошенные мужчины в большей степени, чем женщины, настроены на отъезд из села. Возможно, у них меньше скреп, связывающих с родной землей, нежели у женщин, хранительниц очага. У мужчин также сильнее проявля- ется миграционная устремленность: $42 \%$ мужчин и $33 \%$ женщин категорически стремятся покинуть село. Эти респонденты не связывают себя с сельским укладом жизни, считая, что здесь нет возможности для создания комфортных условий жизни $(24,6$ \%), их дети не желают жить в деревне (13,2\%). Поэтому бесперспективность, затянувшаяся деградация села усиливают миграцию селян.

Определенная часть респондентов, почти пятая часть, свои оптимистичные ожидания связывают с тем, что придет хороший руководитель, который способен эффективно вести хозяйство. В таком случае эти респонденты не покинут сельские просторы.

Полученные результаты свидетельствуют, что более трети опрошенных (39,3\%), наоборот, хотят жить в родном селе, где условия жизни приближены к городским $(13,2 \%)$, предоставлены возможности для личностного развития (12,6 \%). Мнение мужчин и женщин по этим позициям совпадает. Однако заметим, что относительно перспектив самореализации на родной земле более позитивно настроены женщины $(17,7 \%)$, нежели мужчины $(9,3$ \%).

\section{Заключение}

Собранный автором в рамках настоящего исследования эмпирический материал показал, что селяне, хотя и полагаются на свои силы, нуждаются в поддержке властей территориально-поселенческого, регионального, федерального уровней. Гипотеза нашего исследования об усилении кризиса в сельских южнороссийских районах, упадке сельхозпроизводства, низком уровне жизни сельского населения подтвердилась. По самооценке, $59 \%$ опрошенных селян являются бедными и обездоленными. Несмотря на улучшение состояния зерноводства, животноводства, увеличение инвестиций в развитие сельских тер-

Распределение ответов на вопрос «Связываете ли Вы свою жизнь с сельской местностью?» (в \%)

\begin{tabular}{|l|c|c|c|}
\hline \multicolumn{1}{|c|}{ Варианты } & Мужчины & Женщины & $\begin{array}{c}\text { Среднее } \\
\text { значение }\end{array}$ \\
\hline $\begin{array}{l}\text { Да, связывают (сумма положи- } \\
\text { тельных вариантов) }\end{array}$ & 35,1 & 43,5 & 39,3 \\
\hline Позиция ожидания & 20,2 & 16,2 & 18,2 \\
\hline Миграционная устремленность & 42,2 & 33,4 & 37,8 \\
\hline
\end{tabular}


риторий, в отрасли не решены важные проблемы: падение без того низких доходов населения, отсутствие рабочих мест, слабая внедряемость новых технологий, рост цен на продовольствие и в то же время инфляция.

Гипотеза о скептическом отношении населения к изменениям в сельской местности также подтвердилась. Половина опрошенных не видят позитивных изменений в селе, где они проживают. Поэтому они не связывают свое настоящее и будущее с сельским укладом, многие из них готовы выехать из села, стремясь решить насущные проблемы, которые связаны в первую очередь с отсутствием средств для удовлетворения жизненных потребностей. Лишь пятая часть опрошенных живет ожиданиями положительных изменений, их решение об отъезде зависит от эффективности ведения хозяйства. Но если не будут преодолены указанные проблемы, то будущее южнороссийских сел печально: ситуацию их исчезновения, заброшенности сельских территорий не остановить с помощью одних деклараций громких программ различных уровней по развитию сельских территорий, аграрной отрасли.

\section{ПРИМЕЧАНИЕ}

${ }^{1}$ Статья подготовлена в рамках государственного задания КалмНЦРАН «Развитие сельских территорий Юга России: комплексный социально-экономический и экологический мониторинг» Рег. № НИОКТР АААА-А19-1190111490037-8.

The article was prepared within the framework of the state task of the KalmSC RAS "Development of rural territories of the South of Russia: integrated socioeconomic and environmental monitoring».

\section{СПИСОК ЛИТЕРАТУРЫ}

Алтухов 2018 - Алтухов А.И. Проблемы развития АПК страны и необходимость их ускоренного решения // Экономика сельского хозяйства России. № 4. С. 2-14.

Бадмаева 2017 - Бадмаева Н.В. Демографический потенциал и проблемы занятости сельского населения южнороссийских регионов // Бюллетень Калмыцкого научного центра РАН. 2017. № 2 (2). C. 110-118.

Бадмаева 2018 - Бадмаева Н.В. Миграция сельского населения южнороссийских регионов: про- блемы, тенденции, направления // Oriental Studies. 2018. № 3 (37). C. 152-164.

Великий 2019 - Великий П.П. Хозяева сельских подворий: дифференциация, проблемы, будущее // Социологические исследования. 2019. № 12. C. 48-60.

Великий, Бочарова 2014 - Великий П.П., Бочарова E.B. Динамика формирования многоканальности источников выживания сельской семьи // Известия Саратовского университета. Новая серия. Серия: Социология. Политология. 2014. Т. 14, № 1. С. 30-37.

Жалсанова 2016 - Жалсанова В.Г. Сельские территории современной России: подходы к исследованию // Социодинамика. № 10. С. 10-15.

Калугина 2016 - Калугина 3.И. Многоукладность аграрной экономики в контексте рационального использования ресурсов // Интерэкспо ГЕО-Сибирь 2016. Т. 3, № 1. С. 128-132.

Минеева 2020 - Минеева Н.Н. Диверсификация экономики как фактор нейтрализации причин бедности // Бедность сельского населения России: генезис, пути преодоления, прогноз. М.: ВИАПИ им. А.А. Никонова, 2020. C. $145-146$.

Муханова 2018 - Муханова М.Н. Сельское население в структурах неформального сектора на рынке труда АПК // Власть. 2018. № 5. C. $125-132$.

Намруева 2020 - Намруева Л.В. Занятость в личных подсобных хозяйствах южнороссийских регионах: итоги исследования // Социологическая наука и социальная практика. 2020. T. 8, № 3 (31). С. 77-97. DOI: 10.19181/ snsp.2020.8.3.7488.

Сальников 2020 - Сальников С.Г. Уровень и структура бедности сельского населения // Бедность сельского населения России: генезис, пути преодоления, прогноз. М.: ВИАПИ им. А.А. Никонова, 2020. С. 15-19.

Хагуров 2009 - Хагуров А.А. Некоторые методологические аспекты исследования российского села // Социологические исследования. 2009. № 2. C. 95-101.

Namrueva 2019 - Namrueva L. Transformation of Collective Patterns in Southern Russian Villages In Early $21^{\text {st }}$ Century // European Proceedings of Social and Behavioural Sciences. 2019. № 58. P. 2399-2406. DOI: 10.15405/epsbs.2019.12.04.321.

Nuskhaeva 2019 - Nuskhaeva B.B. Economic Situation of the Rural population in the Southern Regions of Russia // European Proceedings of Social \& Behavioural Sciences. 2019. № 58. P. 2503-2509. DOI: 10.15405/epsbs.2019.12.04.335. 


\section{REFERENCES}

Altukhov A.I., 2018. Problems of Development of the Country's Agro-Industrial Complex and the Need for Their Accelerated Solution. Ekonomika sel'skogo khozyajstva Rossii, no. 4, pp. 2-14.

Badmaeva N.V., 2017. Demographic Potential and Problems of Employment of the Rural Population of the Southern Regions. Byulleten' Kalmyckogo nauchnogo centra RAN, no. 2 (2), pp. 110-118.

Badmaeva N.V., 2018. Migration of the Rural Population of the Southern Russian Regions: Problems, Trends, Directions. Oriental Studies, no. 3 (37), pp. 152-164.

Veliky P.P., 2019. The Owners of Rural Farmsteads: Differentiation, Problems, and the Future. Sociologicheskie issledovaniya, no. 12, pp. 48-60.

VelikiyP.P., Bocharova E.V., 2014. Dynamics of Formation of Multichannel Sources of Rural Family Survival. Izvestiya Saratovskogo universiteta. Novaya seriya. Seriya: Sociologiya. Politologiya, vol. 14, no. 1, pp. 30-37.

Zhalsanova V.G., 2018. Rural Territories of Modern Russia: Approaches to Research. Sotsiodinamika, no. 10, pp. 10-15.

Kalugina Z.I., 2016. Diversity of the Agricultural Economy in the Context of Resource Management. Interekspo GEO-Sibir', vol. 3, no. 1, pp. 128-132.
Mineeva N.N., 2020. Economic Diversification As a Factor of Neutralizing the Causes of Poverty. Bednost'sel'skogo naseleniya Rossii: genezis, puti preodoleniya, prognoz. Moscow, VIAPI Named after A.A. Nikonov, pp. 145-146.

Mukhanova M.N., Rural Population in the Structures of the Informal Sector in the Labor Market of Agriculture. Vlast', no. 5, pp. 125-132.

Namrueva L.V., 2020. Employment in Private Farms of the South Russian Regions: The Results of the Study. Sociologicheskaya nauka i social'naya praktika, vol. 8, no. 3 (31), pp. 77-97.

Salnikov S.G., 2020. The Level and Structure of Rural Population Poverty. Bednost'sel'skogo naseleniya Rossii: genezis, puti preodoleniya, prognoz. Moscow, VIAPI Named after A.A. Nikonov, pp. 15-19.

Hagurov A.A., 2009. Some Methodological Aspects of the Study of the Russian Village. Sociologicheskie issledovaniya, no. 2, pp. 95-101.

Namrueva L., 2019. Transformation of Collective Patterns in Southern Russian Villages In Early $21^{\text {st }}$ Century. European Proceedings of Social and Behavioural Sciences, no. 58, pp. 23992406. DOI: 10.15405/epsbs.2019.12.04.321.

Nuskhaeva B.B., 2019. Economic Situation of the Rural population in the Southern Regions of Russia. European Proceedings of Social \& Behavioural Sciences, no. 58, pp. 2503-2509. DOI: 10.15405/ epsbs.2019.12.04.335.

\section{Information About the Author}

Ludmila V. Namrueva, Candidate of Sciences (Sociology), Associate Professor, Leading Researcher, Department for Complex Monitoring and Information Technologies, Kalmyk Scientific Center of the Russian Academy of Sciences, Ilishkina St, 8, 358000 Elista, Russian Federation, lnamrueva@yandex.ru, https://orcid.org/0000-0001-7805-8710

\section{Информация об авторе}

Людмила Васильевна Намруева, кандидат социологических наук, доцент, ведущий научный сотрудник отдела комплексного мониторинга и информационных технологий, Калмыцкий научный центр РАН, ул. Илишкина, 8, 358000 г. Элиста, Российская Федерация, lnamrueva@yandex.ru, https://orcid.org/0000-0001-7805-8710 